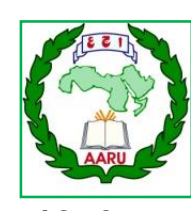

مجلة اتحاد الجامعات العريبة للعلوم الزراعية ، جامعة عين شمس ، القاهرة ، مصر

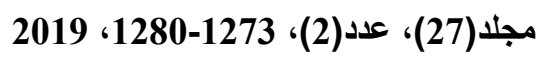

Website: http://ajs.journals.ekb.eg

دراسة اقتصادية لبعض مزارع دجاج بارى التسمين بمحافظة القليوبية

[106]

\author{
صفية محمد أمين حبيشى" - محمد بلير العراقي - ثناء النوبى أحمد سليم

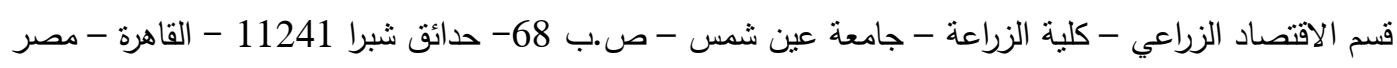

*Corresponding author: safyamohamed26@agr.asu.edu.eg

Received 13 April, 2019

Accepted 30 April, 2019

1- متوسط عدد مزارع بدارى التسمين بلغ نحو 1.6 ألف مزرعة بنسبة 6.67\% من بن إجمالى أعداد المزارع على مستوى محافظة القليوبية . 2- بدراسة أهم المشاكل والمعوقات التى تواجه مربى التئي

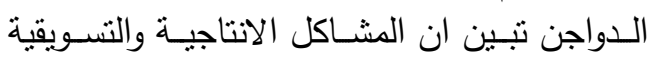

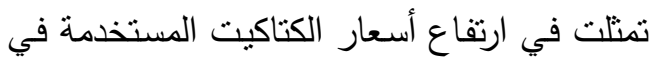

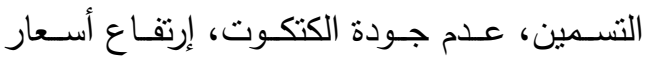
العلف، قلة العمالة المدربة، مشكلة تحكم التجار

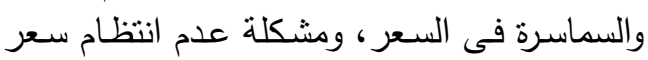
السوق 3- من خـلال تقسيم عينة الدراسة الى ثنلاث سعات

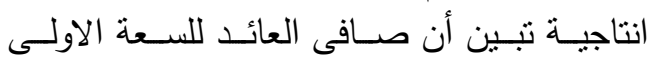

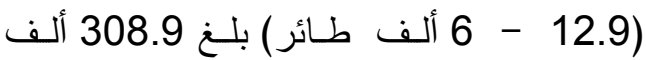
جنيه / دورة، وصـافى العائد للسعة الثانية (أقل

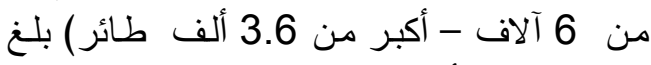

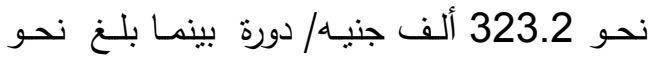

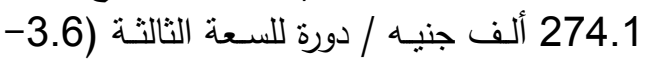
0.8 ألف طائر).

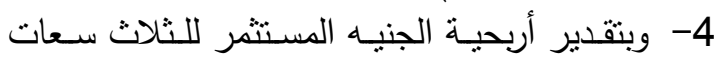

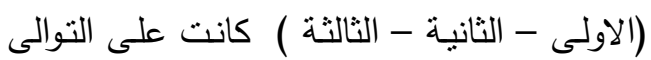
1.05، 1.12 ، 1.31 الف جنيه . الفانه

الكلمات الدالة: الدورة الانتاجية ، الطاقات الانتاجية الكلية، الطاقات الانتاجية الفعلية، بدارى التسمين الألين
تعتبر صناعة الدواجن فى مصر من أهم

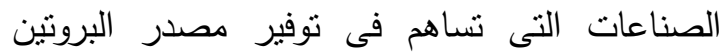

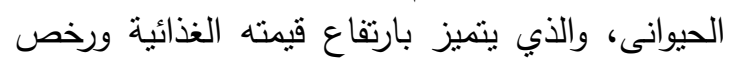

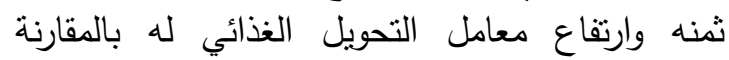

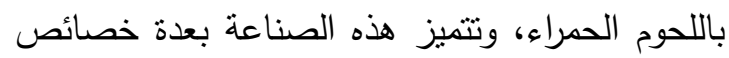

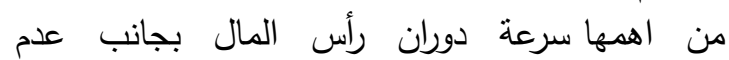

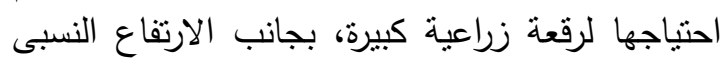

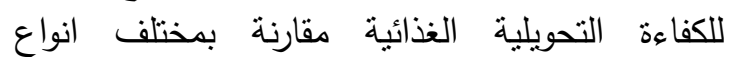

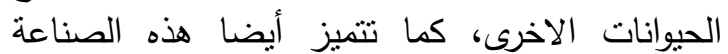
بارتفاع العائد وانخفاض رأس المال المطلوب للاستثمار في هذا المجال بالمقارنة بالمشاريع الإنتاجية الأخرى.

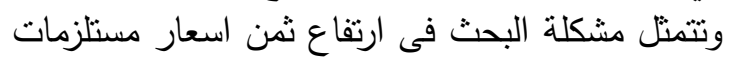

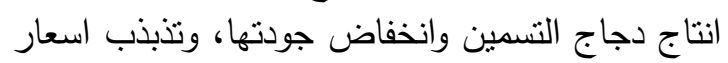

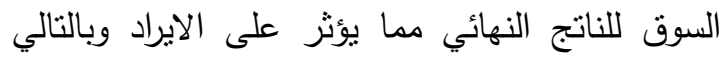

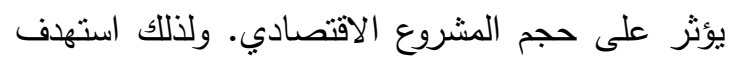

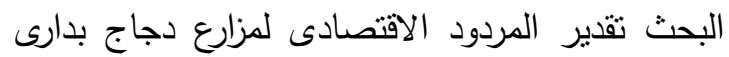

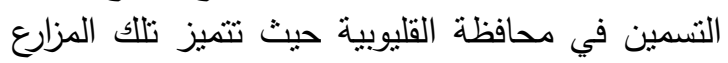

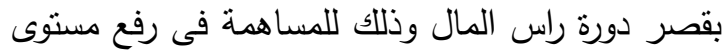

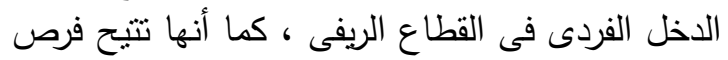

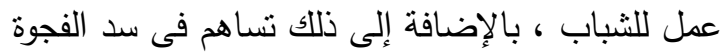
الغذائية للفرد من احتياجاته من البروتين الحيوانى، لإني،

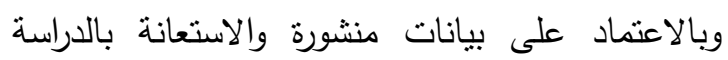

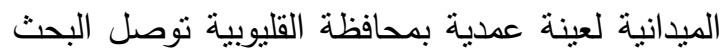

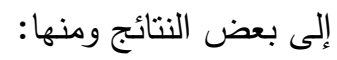


الاقتصادية مثل اجمالى الايرادات وصافى العائد

$$
\text { وأربحية الجنية . }
$$

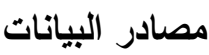

اعتمدت الدراسة على البيانات الثانوية المنشورة من

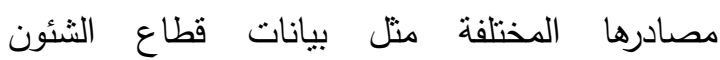
الاقتصادية بوزارة الزراعة . كما أعتمدت الدراسة بصفة أساسية على البيانات

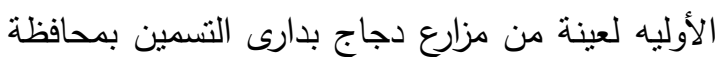

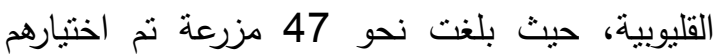

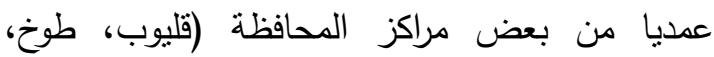
الخانكة، شبين القناطر، القناطر الخيرية).

\section{نتائج البحث}

(1) تطور أعداد مزارع بارى التسمين على مستوى محافظة القليوبية يبين الجدول رقم (1) تطور أعداد مزارع بدارى التسمين خلال الفترة (2016/2007) فى محافظة القليوبية، حيث بلغت نحو 1.721 ألف مزرعة في في في بداية فترة الدراسة أى عام 2007 ، ثم حدث تذانبذب

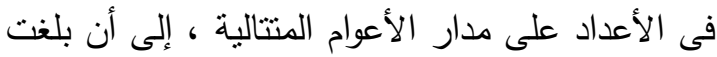

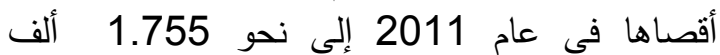
مزرعة، ثم حدث تغير فى الاعداد بالزيادة والنقصان

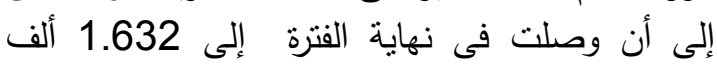

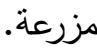

(2) تطور أعداد العنابر العاملة لمزارع بدارى التسمين على مستوى محافظة القليوبية أعناية من المنطقى أن يكون هنالك ارتباط بين أعداد العداد

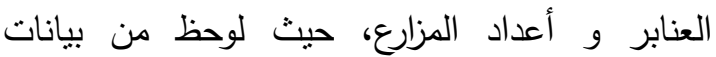
الجدول رقم (1)، تطور أعداد العنابر العاملة خلال الفترة (2016/2007) فى محافظة القليوبية ، أن النابل أعداد العنابر العاملة فى محافظة القليوبية بلغت أدناها

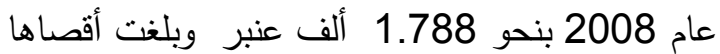

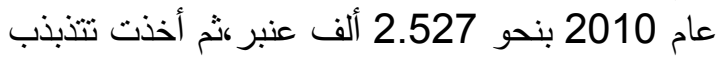
بالزيادة والنقصان إلى أن وصلت فى نهاية فترة الدراسة

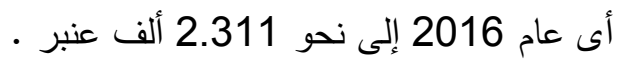

\section{مقدمـة}

تعتبر صناعة الدواجن فى مصر من اهم الصناعات التى تسهر فى توفير مصدر البرونين

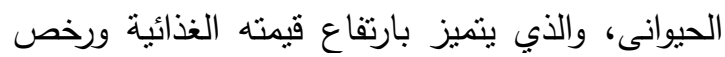
ثمنه وارتفاع معامل التحويل الغذائي له بالهالئل بالمقارنة باللحوم الحمراء. وتتميز هذه الصناعة بعدة خصائص

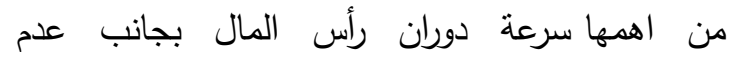

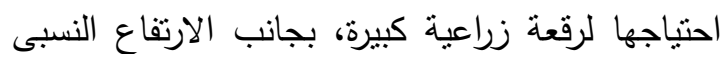

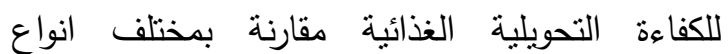

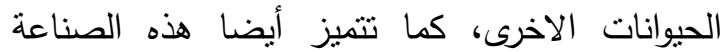

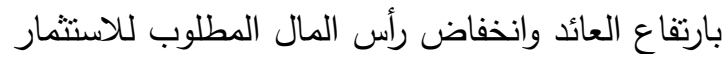

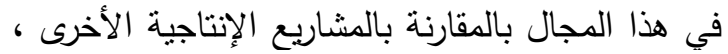

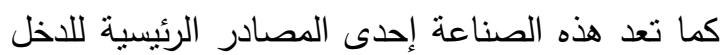

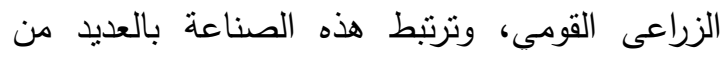
الصناعات الأخرى منل صناعة الزيط الأعلاف الحيوانية بالعية

$$
\text { والأدوية والمستلزمات البيطرية. }
$$

\section{مشكلة البحث}

تتمثل مشكلة البحث فى ارتفاع اسعار مستلزمات انتاج دجاج التسمين وانخفاض جودتها، وتذبذب اسعار التهار

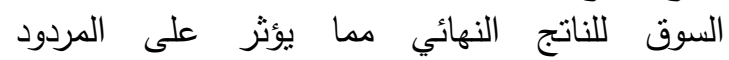
الاقتصادى للوحدة الانتاجية.

\section{هاف البحث}

يهدف البحث إلى دراسة المردود الاقتصادى لمزارع دجاج بدارى التسمين حيث تتميز بقصر دورة راس لاس لفردي المال وذلك للمساهمة فى رفع مستوى الدخل الفردى فى لقى القطاع الريفى، وسد الفجوة الغذائية للفرد من احتياجاته

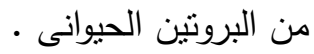

\section{الطريقة البحثية}

أعتمدت الدراسة على استخدام أسلوب التحليل

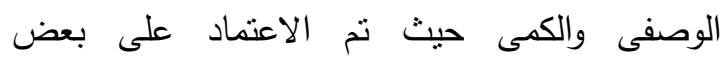
الأساليب كالمتوسطات والأهمية النسبية وأساليب الانحدار البسيط وأيضا أستخدام بعض المؤشئ النشرات 
فترة الدراسة عام 2016 حيث بلغت 57.17 مليون

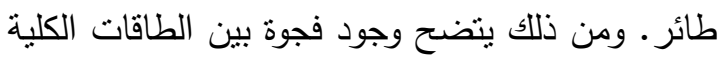

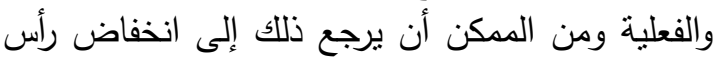

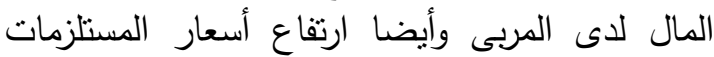

للانتاج وظهور بعض الأمراض خلال تللك الفترة.

تظور المؤثرات الإنتاجية لاجاج بداري التسمين

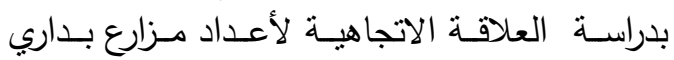

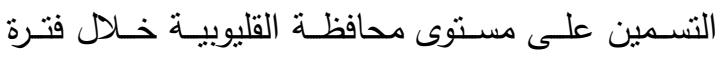
الدراسة (2007-2016) تبين من معادلة (1) بجدول

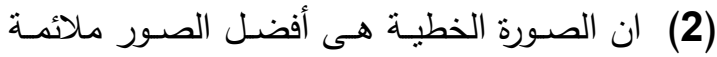

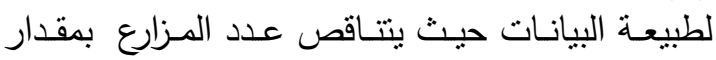

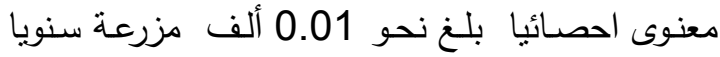

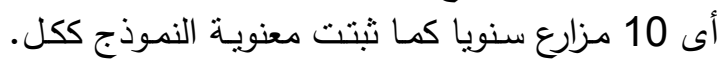

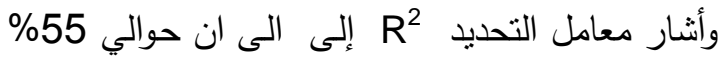

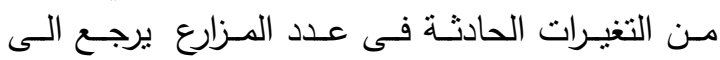

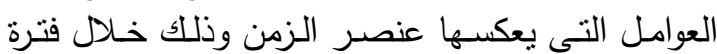

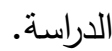

بدراسة العلاقة الاتجاهية لعدد العنابر العاملة

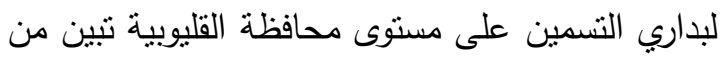

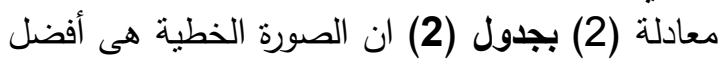

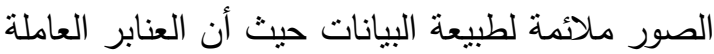

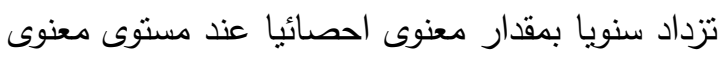

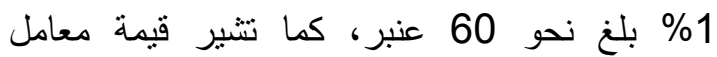

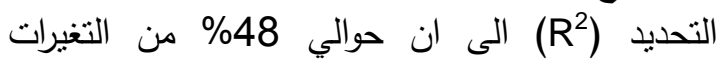

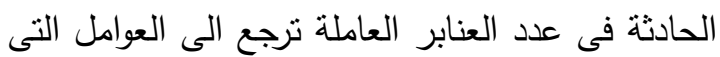
يعكسها عنصر الزمن وذللك خلال الفترة (2016) 2016)، كما ثبت معنوية النموذج ككل

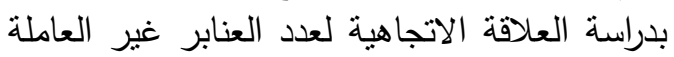

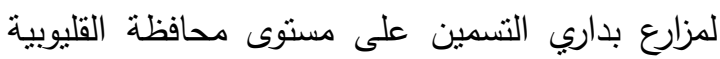

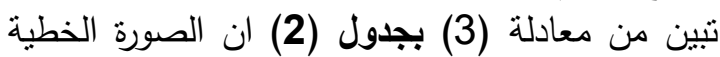

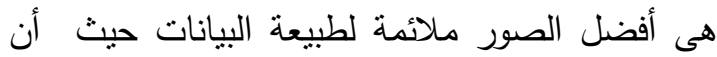

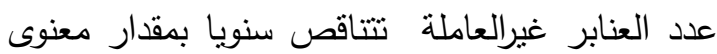

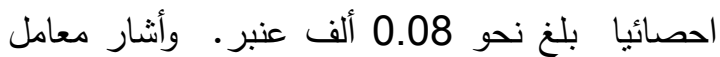

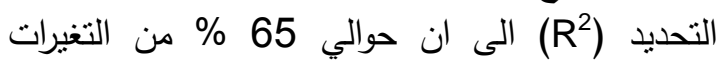

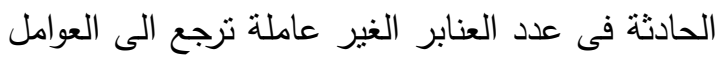

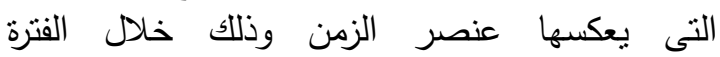
.2016-2007)
(3) تطور أعداد العنابر غير العاملة لمزارع بدارى التسمين على مستوى محافظة القليويية

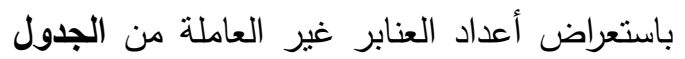
رقم (1) تبين أن أعداد العنابر غير العاملة في بداية

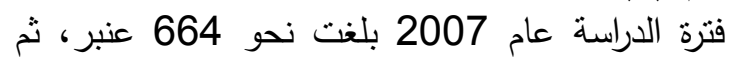
أخذت بعد ذلك بالتزايد والتتاقص إلى أن بلغ بلغت في في

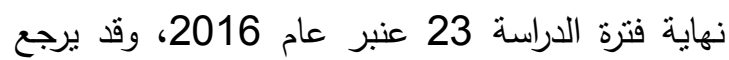
وجود تلك العنابر غير العاملة إلى ارتفاع أسعار

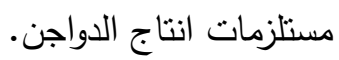

(4) تطور إجمالى العنابر لمزارع بدارى التسمين على مستوى محافظة القليوبية بيين الجدول رقم (1) تطور اجمالى العنابر بمزارع

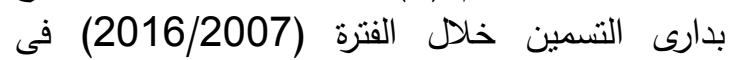
محافظة القليوبية، حيث بلغت أدناها عام 2011 بنحو 2.251 ألف عنبر، ثم حدث تغير في الفي الأعداد

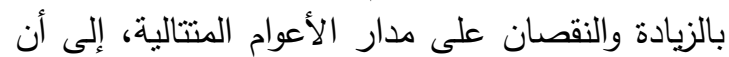
بلغت فى نهاية فترة الدراسة أى عام 2016 نحو 2.9 ألف عنبر ، وكان منتسط إجمالى العنابر فى نلإلك الفترة بلغ نحو 2.398 ألف عنبر منوسط الف

(5) تطور الطاقات الانتاجية الفعلية لمزارع بار

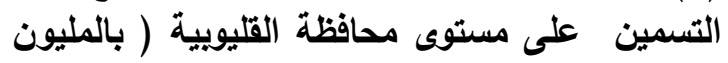
طائر ) يبين الجدول رقم (1)، تطور الطاقات

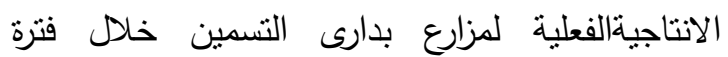

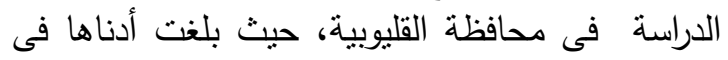
بداية فترة الدراسة أى عام 2007 نحو 34.63

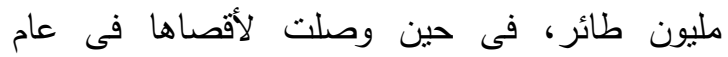
2010 نحو 53.59 مليون طائر وفى نهاية فنرة الدراسة وصلت الى 47.30 مليون طائر عام 2010 فئر

(6) تطور الطاقات الانتاجية الكلية لمزارع بدارى التسمين على مستوى محافظة القليويية (بالمليون طائر)

من خلال البيانات الموجودة فى جدول (1)، تبين انه فى بداية فترة الدراسة عام 2007 بلغت الغات الطاقيات

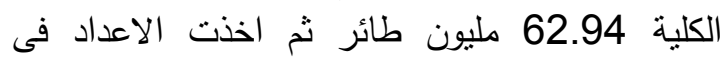
التذبذب بالارتفاع والانخفاض الى ان وصلت فى نهاية 
جدول 1. النظور الزمنى للمؤشرات الانتاجية لمزارع بدارى التنمين على مستوى محافظة القليوبية خلال الفترة (2016/2007)

\begin{tabular}{|c|c|c|c|c|c|c|}
\hline \multicolumn{2}{|c|}{ الطاقات الانتاجية (بالمليون طائر) } & \multicolumn{3}{|c|}{ عدد العنابر (بالألف عنبر) } & \multirow{2}{*}{ عزالألفزارع } & \multirow[b]{2}{*}{ 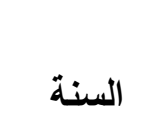 } \\
\hline الفعلية & 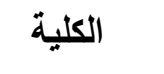 & 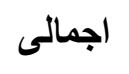 & غير عاملة & 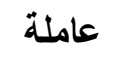 & & \\
\hline 34.63 & 62.94 & 2.507 & 0.664 & 1.843 & 1.721 & 2007 \\
\hline 35.96 & 62.46 & 2.498 & 0.710 & 1.788 & 1.713 & 2008 \\
\hline 37.53 & 62.11 & 2.520 & 0.598 & 1.922 & 1.727 & 2009 \\
\hline 53.59 & 64.43 & 2.556 & 0.029 & 2.527 & 1.741 & 2010 \\
\hline 44.94 & 55.63 & 2.251 & 0.024 & 2.227 & 1.755 & 2011 \\
\hline 46.51 & 57.44 & 2.322 & 0.024 & 2.298 & 1.604 & 2012 \\
\hline 45.96 & 57.98 & 2.320 & 0.024 & 2.296 & 1.618 & 2013 \\
\hline 46.20 & 57.06 & 2.333 & 0.023 & 2.310 & 1.633 & 2014 \\
\hline 46.80 & 57.06 & 2.334 & 0.023 & 2.311 & 1.633 & 2015 \\
\hline 47.30 & 57.17 & 2.334 & 0.023 & 2.311 & 1.632 & 2016 \\
\hline 34.63 & 55.63 & 2.251 & 0.023 & 1.788 & 1.604 & الحد الادنى \\
\hline 53.59 & 64.43 & 2.556 & 0.710 & 2.527 & 1.755 & الحد الاعلى \\
\hline 43.94 & 59.43 & 2.398 & 0.214 & 2.183 & 1.678 & المتوسط \\
\hline
\end{tabular}

المصدر: جمعت وحسبت من بيانات وزارة الزراعة واستصلاح الأراضى، قطاع الشئون الاقتصادية، الادارة المركزية للاقتصاد الزراعى، احصائيات الثزروة الحيوانية والداجنة- أعداد مختلفة.

جدول 2. تقديرات الاتجاه العام الزمني للمؤشرات الإنتاجية بمزارع بداري التنمين علي مستوي محافظة القليوبية

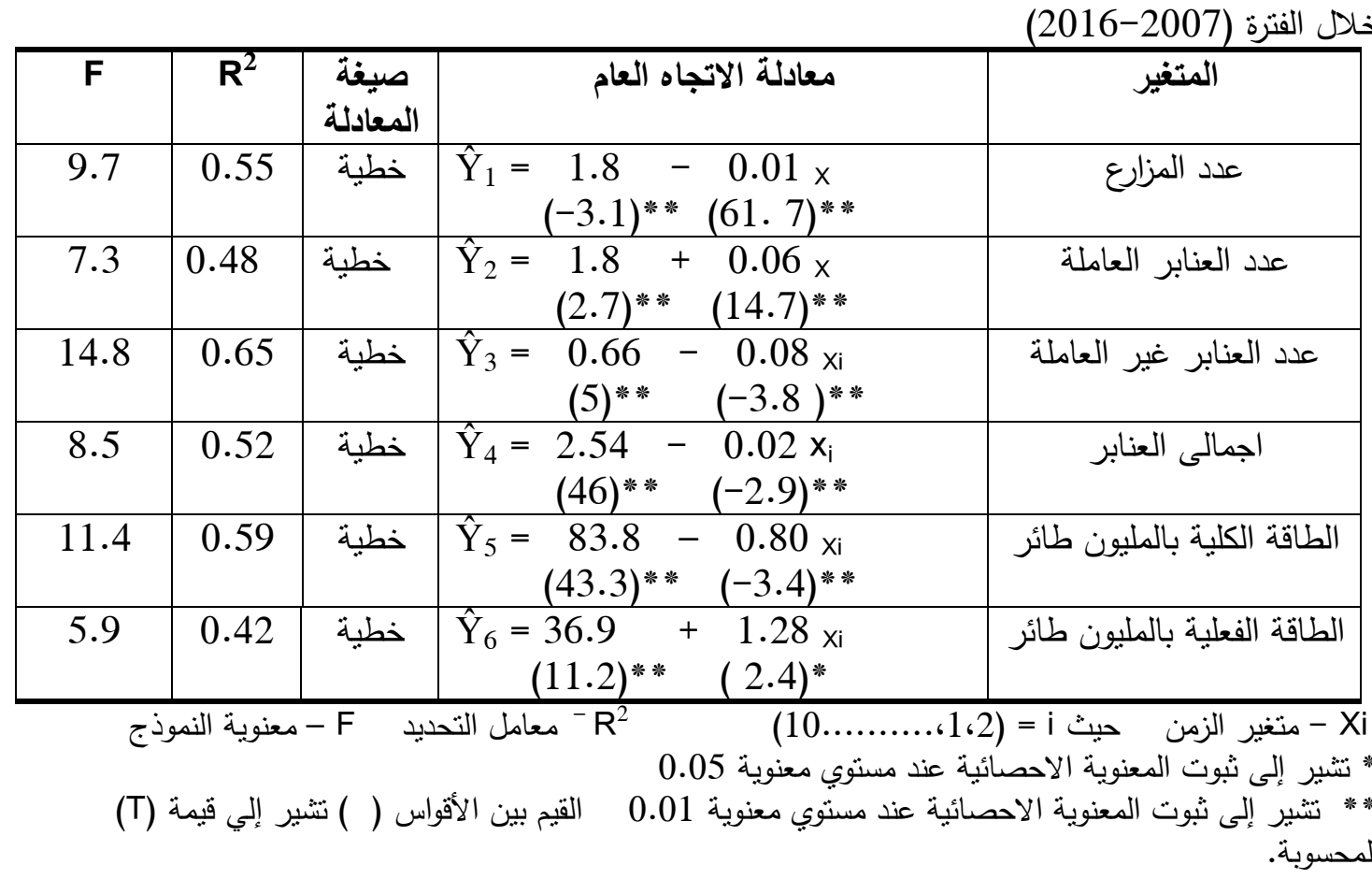

المصدر : جمعت وحسبت من بيانات الجدول (1) . 


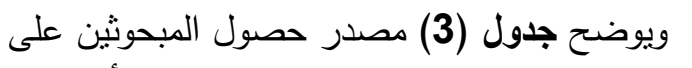

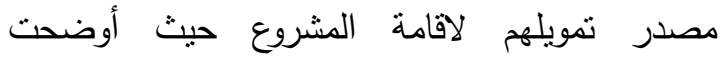

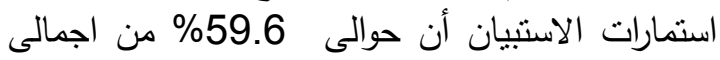

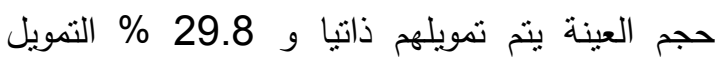
بالمشاركة و10.6 \% يقوموا بعملية الاقتراض لاقامة مشروعهم من بنأك مصر الزراعى .

جدول 3. توزيع العينة وفقا لمصدر التمويل

\begin{tabular}{|c|c|c|}
\hline$\%$ & تكرارات & مصدر التمويل \\
\hline 6.59 & 28 & تمويل ذاتي \\
\hline 29.8 & 14 & مشاركة \\
\hline 10.6 & 5 & اقراض \\
\hline 100 & 47 & الإجمالي \\
\hline
\end{tabular}

المصـدر : جمعت وحسبت مسن بيانـات استمارة الاستنبيان

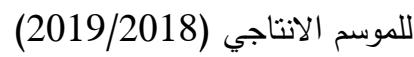

مصدر الحصول على الاعلاف

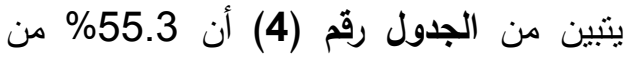
المربيين يحصلون على الأعلاف اللازمة لتربية الدجاج

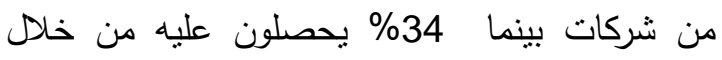

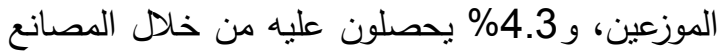
و 6.4 \% من خلال ناجر التجزئة.

جدول 4. مصادر الحصول على الأعلاف

\begin{tabular}{|c|c|c|}
\hline$\%$ & تكرارات & مصدر العلف \\
\hline 55.3 & 26 & شركة \\
\hline 34 & 16 & موزع \\
\hline 4.3 & 2 & مصنع \\
\hline 6.4 & 3 & تاجر تجزئة \\
\hline 100 & 47 & الإجمالي \\
\hline
\end{tabular}

للموسم الانتاجي (2019/2018)
بدراسة العلاقة الاتجاهية للإجمالى عددالعنابر لمزارع بداري التسمين على مستوى محافظة القليوبية خلال فترة الدراسة (2007-2016) تبين من معادلة

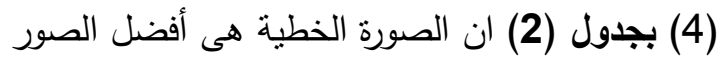

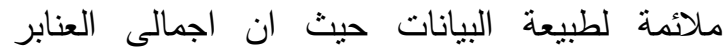

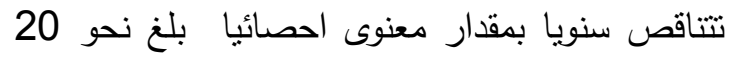

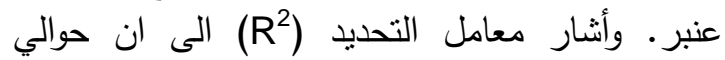

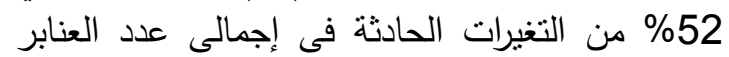

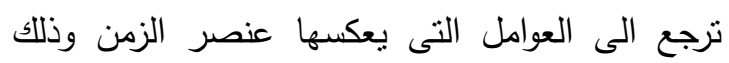
خلال الفترة (2007-2016). وبدراسة العلاقة الاتجاهية للطاقات الانتاجية الكلية لبداري التسمين على مستوى محافظة القليوبية خلال

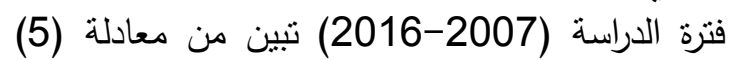
بجدول (2) ان الصورة الخطية هى أفضل الصنور

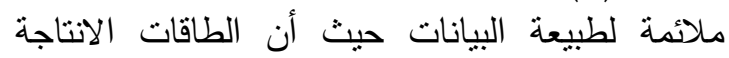

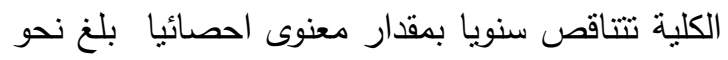

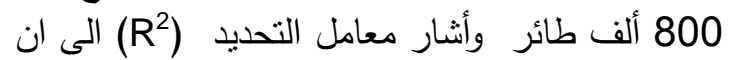

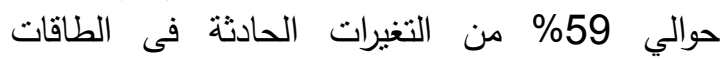

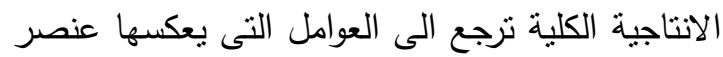
الزمن وذلك خلال الفترة (2007-2016).

بدراسة العلاقة الاتجاهية للطاقات الانتاجية الفعلية لمزارع بداري التسمين على مستوى محافظة القليوبية خلال فترة الدراسة (2007-2016) تبين من معادلة

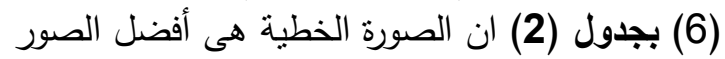
ملائمة لطبيعة البيانات حيث ان ان الطاقات الانتاجية الناتية الفعلية تزداد بمقدار معنوى احصائيا بلغ نحو لمانية 1.28

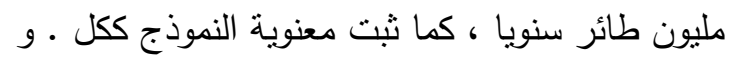

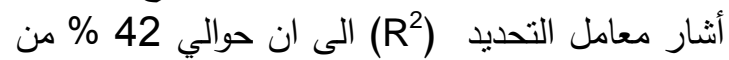
التغيرات الحادثة فى الطاقات الانتاجية الفعلية ترجع النع

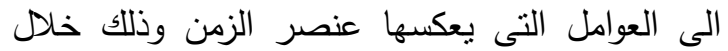
الفترة (2007-2016).

\section{* عينة الدراسة}

توضح عينة الدراسة الميدانية وفقا لاستمارات

الاسنبيان التى اختيرت عمدية بمحافظة القليوبية أن الن النيات حجم العينة بلغ نحو 47 مزرعة للموسم الانتاجى الانى .2019/2018) 
جدول 6. أهم المشاكل والمعوقات التي تواجه مربى

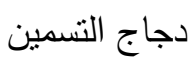

\begin{tabular}{|c|c|c|c|}
\hline$\%$ & التكرار & البيـــان & \\
\hline 93.6 & 44 & ارتفاع ثن الكتكوت & \multirow{5}{*}{ المالكتاكيت } \\
\hline 8.5 & 4 & عدم الحصول على الكمية & \\
\hline 76.6 & 36 & عدم جودة الكتكوت & \\
\hline 6.4 & 3 & عدم وصول الكتكوت في & \\
\hline 63.8 & 30 & أن يكون الكتكوت حامل & \\
\hline 8.5 & 4 & عدم توافر العلف & \multirow{6}{*}{ المتشعلقة } \\
\hline 4.3 & 2 & عدم التوافق بين العرض & \\
\hline 100.0 & 47 & أسعار العلف مرتفعة & \\
\hline 6.4 & 3 & عدم استلام العلف في & \\
\hline 29.8 & 14 & سوء التخزين & \\
\hline 23.4 & 11 & عدم تعامل الثركة مع المربى مباشرة & \\
\hline 83.0 & 39 & قلة الأيدي العاملة المدربة & \multirow{3}{*}{ المشتعلقة } \\
\hline 63.8 & 30 & ارتفاع الأجر & \\
\hline 31.9 & 15 & الرضاء عن العمالة & \\
\hline 4.89 & 24 & تحكم التجار والسماسرة فى & \multirow{3}{*}{ التسويق } \\
\hline 100.0 & 47 & عدم انتظام أسعار السوق & \\
\hline 863. & 30 & انخفاض سعر البيع عن & \\
\hline
\end{tabular}

المصدر: جمعت وحسبت من بيانات استمارة الاستبيان للموسم

الانتاجي (2019/2018)
مصدر الحصول على الكتاكيت تبين من الجدول رقم (5) أن الغالبية العظمى من النداك

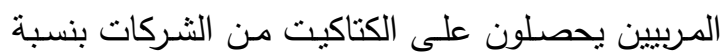

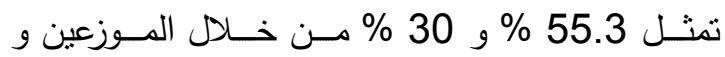
14.7 \% يقومسون بشـراء الكتاكيت اللازمـة من خــاء

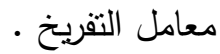
جدول 5. توزيع العينة وفقا لمصدر الحصول على الكتكوت

\begin{tabular}{|c|c|c|}
\hline$\%$ & تكرارات & مصدر الكتكوت \\
\hline 55.3 & 26 & شركة \\
\hline 30 & 41 & موزع \\
\hline 14.7 & 7 & معمل تفريخ \\
\hline 100 & 47 & الإجمالي \\
\hline
\end{tabular}

المصدر: جمعت وحسبت من بيانات استمارة الاستيان للموسم الانتاجي (2019/2018)

المشاكل والمعوقات التي تواجه مربى دجاج التسمين

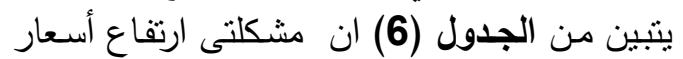

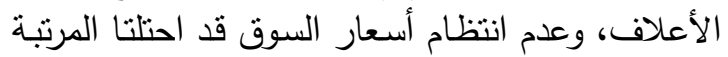

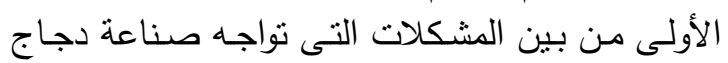
بدارى التسمين فى محافظة القليوبية ، حيث بلغت نسبن التهبة

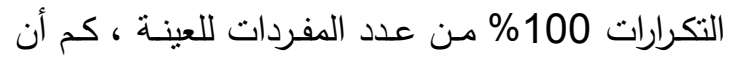

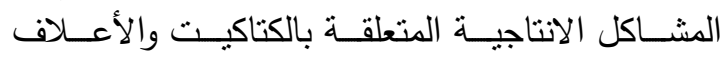

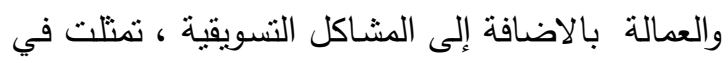

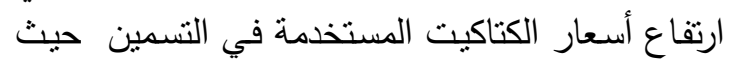

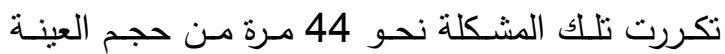
بنسبة 93.6\%، وعدم جودة الكتكوت تكررت نحرة 34 نحو 36

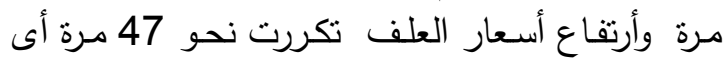

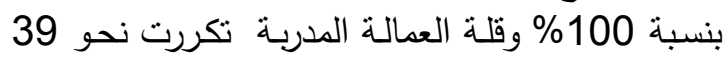
مرة من حجم العينة، ومشكلة تحكم التجار والسماسرة

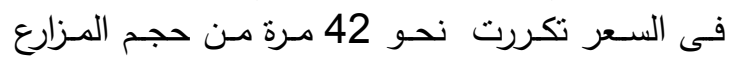
ومشكلة عدم انتظام سعر السوق تكررت نحو 47 مرة من حجم المزارع أى بنسبة 100\% معنم الكرق 
حساب أربحية الجنية المستثرللفئة الأولي بلغ نحو

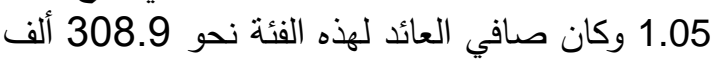

جنية/للاورة خلال الموسم المشار إليه. أما السعة الانتاجية الثانية فكان متوسط الئها اليراد الدورة

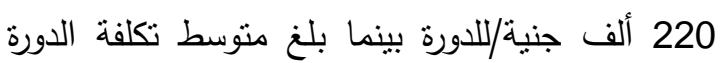
نحو 197 ألف جنية/للاورة وتم حساب أربحية الجنية

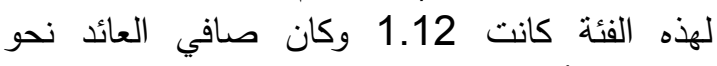
323.16 ألف جنية/للاورة لهذه الفئة لذلك الموسم.

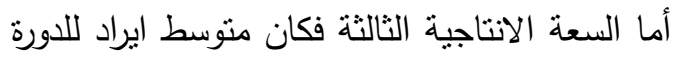

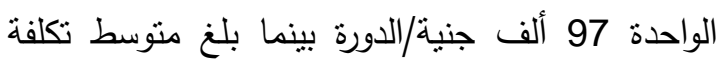

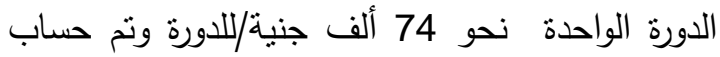
أربحية الجنية لهذه الفئة كانت 1.31 وكان الاندة صافي العائد نحو 274.15 ألف جنيه/للاورة لذلك الموسم.
العائد الاقتصادي لمزارع بدارى التسمين

• عائد الجنية من السعة الانتاجية للعنبر الواحد

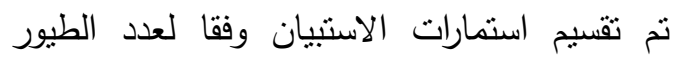

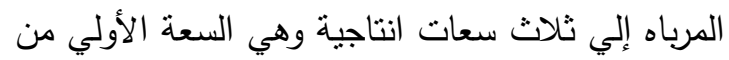

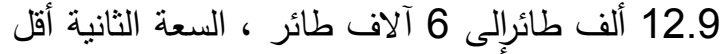

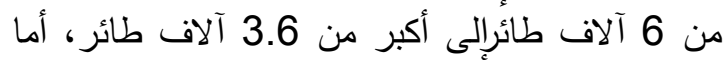

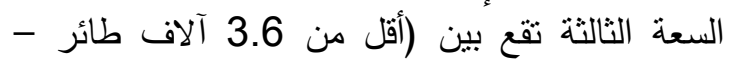
0.8 آلاف طائر).

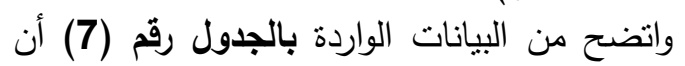

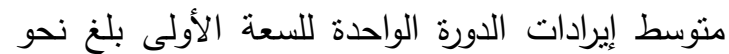
291 ألف جنية/للاورة واتضح أيضا أن متوسط تكلفة التهة الدورة بلغ نحو 276 ألف جنية/للاورة ومن ذلك تن التصن

جدول 7. أربحية الجنية وصافي العائد لمزارع بدارى النسمين

\begin{tabular}{|c|c|c|c|c|c|c|c|}
\hline \multirow{2}{*}{ (ألف جنية/الدورة) } & \multirow{2}{*}{ الربنية المستثر } & \multicolumn{2}{|c|}{ 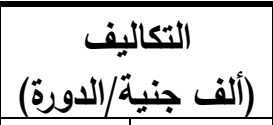 } & \multicolumn{2}{|c|}{ 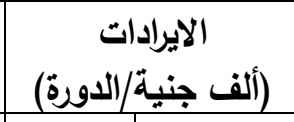 } & \multirow[t]{2}{*}{ عدد المزارع } & \multirow{2}{*}{ ( السعة الانتاجية } \\
\hline & & |المتوسط & الاجمالى & المتوسط & الاجمالى & & \\
\hline 308.9 & 1.05 & 276.5 & 5806.2 & 291.2 & 6115.1 & 21 & $(6-12.9)$ \\
\hline 323.16 & 1.12 & 197.2 & 2760.6 & 220.3 & 3083.76 & 14 & 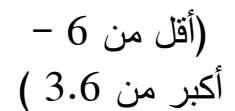 \\
\hline 274.15 & 1. 31 & 74.45 & 893.35 & 97.3 & 1167.5 & 12 & $(0.8-3.6)$ \\
\hline
\end{tabular}

المصدر: جمعت وحسبت من نتائج استمارة استيان المزارع للموسم الانتاجى

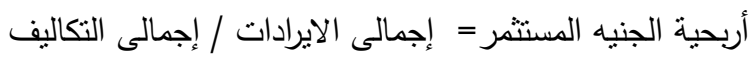
صافى العائد = اجمالى الايرادات - اجمالى التكاليف الإيف

\section{المــراجـع}

لذا يوصى البحث فى ضوء النتائج البحثية ما يلى

وزارة الزراعة واستصلاح الاراضى 2007 - 2016.

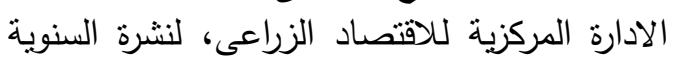

للاقتصاد الزراعى، أعداد متفرقة. لإداد.

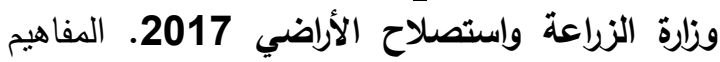

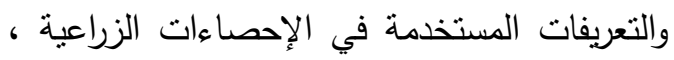
قطاع الشئون الاقتصادية.
1. العمل على نشر ثقافة التدريب وذلك لتوفير العمالة

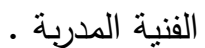
2.نوفير حملات توعية بيطرية ، وتوفير أمصال ولقحات فعالة. 3. تفعيل الرقابة على منتجات الأعلاف للتغلب على فلى الغش فى مكونات العلف. 


\title{
AN ECONOMIC STUDY OF SOME BROILER FARMS IN QALUBIA GOVERNORATE
}

\author{
Safya M.A. Hebaishy ${ }^{\star}$, El-Eraky M.B. and Thanaa E.A. Seleem \\ Agric. Economics Dept., Fac. of Agric., Ain Shams Univ., P.O. Box 68, Hadayek Shobra11241, \\ Cairo, Egypt \\ *Corresponding author: safyamohamed26@agr.asu.edu.eg \\ Received 13 April, 2019 \\ Accepted 30 April, 2019
}

\begin{abstract}
The poultry industry in Egypt is one of the most important industries that contribute in providing the source of animal protein, which is characterized by high nutritional value, cheap price and high conversion coefficient of food compared to red meat. This industry is characterized by several characteristics, the most important speed of turnover of capital as well as not need a large agricultural patch, In addition to the relative increase in food conversion efficiency compared to other types of animals. The industry is also characterized by high return and low capital required to invest in this field compared to other productive projects. The problem of research is the high price of the prices of the inputs of the production of poultry and the low quality of the market, and fluctuation of market prices of the final output, which affects the revenue and thus affect the size of the economic project. Therefore, the study aimed at estimating the economic yield of the poultry farms in the fattening nurseries in Qalyubia governorate. These farms are characterized by a short cycle of the capital cycle in order to contribute to raising the level of individual income in the rural sector. It also provides job opportunities for young people. Of the animal protein, and based on published data and the use of field study for a sample of the municipality of Qalyubia, the research reached some results, including:
\end{abstract}

1- The average number of farms of broiler fattening was about 1.6 thousand farms by $6.67 \%$ of the total number of farms at the level of the province of Qalyubia.

2- The study of the most important problems and obstacles facing the poultry growers found that the problems of production and marketing were the high prices of chicks used in fattening, lack of quality chick, high feed prices, the lack of trained labor, the problem of control of traders and brokers in price, and the problem of irregular market price .

3- By dividing the sample of the study into three production capacities, it was found that the net yield of the first capacity (12.9-6 thousand birds) amounted to 308.9 thousand pounds / cycle, and net return of the second capacity (less than 6 thousand - more than 3.6 thousand birds) LE 323.2 thousand / cycle, while it amounted to about 274.1 thousand pounds / cycle for the third capacity (3.6 - 0.8 thousand birds).

4- The estimated profitability of the pound for the investor for the three capacities (first, second and third) was respectively $1.05,1.12,1.31$ thousand pounds.

Keywords: Production cycle, Total productive capacity, Actual production capacity, Broiler

$$
\text { تحكيم: 1.د سلوى محمد أحمد عبد المنعم } 1 \text { أد على أبو ضيف محمد مطاوع }
$$

